\title{
Evaluation of the Effect of Core Training on the Leap Power and Motor Characteristics of the 14-16 Years Old Female Volleyball Players
}

\author{
Ömer Faruk Bilici ${ }^{1}$, Muzaffer Selçuk ${ }^{1}$ \\ ${ }^{1}$ Van Yüzüncü Y1l University, Pyhsical Education and sport department, Van, Turkey \\ Correspondence: Muzaffer Selçuk, Van Yüzüncü Yıl University, Physical Education and sport department, Van, Turkey.
}

Received: February 15, 2018

Accepted: March 8, 2018

Online Published: March 16, 2018

doi:10.11114/jets.v6i4.3031

URL: https://doi.org/10.11114/jets.v6i4.3031

\begin{abstract}
In this study, it was aimed to assess the effects of core training on the vertical jump strength and some motor characteristics of 14-16 aged female volleyball players. Thirty-four female athletes playing volleyball in Van province participated in the study voluntarily. The average age of volleyball players is 15.47 , the weight average is $53.66 \mathrm{~kg}$ and the average height is $164.29 \mathrm{~cm}$. The athletes participating in the study were randomly divided into two groups as control groups $(n=17)$ and experimental groups $(n=17)$. Control group joined only the volleyball training. Experimental group participated in the 10-week, 3-days-a-week core training in addition to the volleyball training. Measurements were taken before and after the study. Intra-group and inter-group, pre-test, post-test values were calculated using SPSS package program. The students' t-test was used to compare pre-training and post-training tests of control group and experimental groups. The paired sample (dependent sample) t-test was used to compare the first and last tests of both groups. Vertical jumping, upper extremity strength, lower extremity strength, strength of the trunk muscles were found to be improved and body fat percentages were found to be decreased in the experimental group. As a result, it can be said that a 10 week core training improved jumping strength and core strength.
\end{abstract}

Keywords: volleyball, core training, jumping strength, female

\section{Introduction}

People adopt scientific and technologically advanced, developing world in a short time and reflect this change in their lifestyles. The effort to adapt to each new situation is one of the most important features of humankind. This adaptation process is reflected in sports games as well as in every field. This development and change has brought many innovations to sporting games. The use of net video cameras in today's volleyball and the use of goal line technology in the soccer can be seen as an example of new developments that technology has provided to the sport. In the same way, various laboratory and field studies are carried out in order to maximize performance in sport. (Özer et al. 2017; Sarikaya, et al. 2016; Atli et al. 2011) As a result of these studies, in order to improve the motor characteristics of the athletes, it is tried to get high efficiency by training in different environments, different elevations, in different age groups (Bilgic et al. 2016; Pancar et al. 2017; Sarikaya, et al. 2017; Gencer et al. 2017) different climatic conditions. However, various tools and new methods have been tried for the development of motor skills of athletes. Scientific researches related to sport are being carried out jointly with many sciences such as physiology, sociology and psychology. As a result of all these studies it is inevitable to work professionally in order to train the athletes at the elite level (Zorba, 2005). As a result of these studies, competition in sport branches has become more intense and the tempo of sports games has increased.

In order to adapt to high-tempo games, the athletes need to be physically at an optimum fitness level. This is a process that requires further overloading, a post-installation compliance requirement, and adaptation to the new situation (Zorba, 2005). Workouts designed to improve the performance of the sports require a balanced and harmonized exercise of work aimed at developing different motor skills. It is important to ensure balanced and harmonious development of all parts of the body, to prevent injuries and to maximize performance. In addition, optimum adjustment of loading and rest intervals is important for performance and development.

Scientific studies carried out in the field of training aim at reaching the highest level of sportive performance by determining physical, cognitive, psychological and physiological elements which affects sportive performance positively or negatively. 
Increasing muscle strength provides a significant advantage in almost all sports. The overall strength of the body is necessary for all sports. The development of the most used muscles in a particular sport can be described as a more specialization of strength. Many methods have been developed as a result of scientific research carried out towards increasing the strength. One of these methods is core training (Mcgill, 2010).

The core region is the center of the body and is a region where internal and external influences and interventions are intense. The well - developed core area will affect the health, the durability, and the life quality of the individual positively. A well-trained core region is required for high-end fitness, optimal performance, injury and injury prevention. Because the development of the core region muscles means the stabilization of the body's balance mechanism and the provision of a proportional force development in the body. Force training without giving importance to the core area will create risks of injury for the athletes and limit their technical skills (Mcgill, 2010). A good core zone will allow the athlete to load more and at the same time ensure that technical movements are displayed more efficiently and well. In a sense, the muscles of the core region constitute the force dynamics of the body. These muscles may not produce as high a force as some muscles in other parts of the body, but they have an important function at the point of transmitting force. This task provides protection to other muscles in the body. An athlete who has welldeveloped core muscles can adapt to overloading easier. Because the core region is strong, it prevents other muscles from being damaged. Proportionally improving the body strength of the athlete will make it easier to learn and apply a technical action (Mcgill, 2010).

\section{Method}

\subsection{Research Objective}

In this study, it was aimed to determine the effects of core training on leap force and some motoric characteristics in 14-16 years old women who play volleyball.

\subsection{Methodological Model of the Research}

The methodological model of the study was the pre-test post-test experimental method.

\subsection{Population of the Research}

14-16 aged female athletes from 2016-2017 academic year Van Sports High School students who played volleyball for at least 1 year constituted the population of the research.

\subsection{Sample of Research}

14-16 aged female athletes from 2016-2017 academic year Van Sports High School students who played volleyball for at least 1 year and voluntarily participated in the study $(\mathrm{n}=34)$ constituted the sample of the research.

\subsection{Core Training Programme}

34 athletes who voluntarily participated in the study were split into the experiment $(\mathrm{n}=17)$ and control $(\mathrm{n}=17)$ groups with randomization method. In the experiment group, 10 different core exercises with their own body weights were applied after volleyball training for 3 days a week for 10 weeks. For the control group, no additional training model was applied except for volleyball training.

In this study, the core training program was planned as 3 days a week for 10 weeks and for 30-40 minutes per day by using Willardson (2014) and Sato and Mokha (2009) surveys. In the training program, 10 different core exercises which were practiced with their own body weights (Annex 1) were applied. Selected core exercises for the training program are planned from low intensity exercise to high intensity exercise. The duration of application, rest period, set and number of replications of each core movement are specified in Annex 1.

\subsection{Data Collection Tools}

\subsubsection{Age}

The ages of the athletes participating in the survey were determined as years by asking themselves.

\subsubsection{Length Measurement}

The stature of the athletes participating in the survey was measured with a $0.01 \mathrm{~cm}$ sensitive grapevine (Pancar et al. 2016). The stature was measured as anatomic posture, bare foot, breathless, head on frontal plane. The value was recorded as $\mathrm{cm}$.

\subsubsection{Body Weight and Body Fat Percentage Measurement}

Plus (aviv 333) bioelectrical impedance was used to measure the body weight and body fat percentage of the athletes participating in the study. Measurements were made with minimum clothes. During the measurement, the athletes were asked to stand on the bare foot on the metal surface of the device and to hold the parts of the device which must be held with both hands and release their arms parallel to the body. Measurements lasted about 1-2 minutes for each athlete and 
the values determined by bioelectrical impedance analyzer were taken as output from the device. With the output from the bioelectric impedance analyzer; body weight and body fat mass measurement values were taken (Zorba, 1999).

\subsubsection{Claw Force Test (Hand Grip Strength)}

The hand grip strength of the athletes participating in the survey was measured by using a takei hand dynamometer (handgrip). The athlete stands to distribute the body weight equally to both legs. The arm measured by dynamometer is taken to side by 15 degree angle from the body and the dynamometer is held in such a way that the value part of it will be out. The athlete tightened the dynamometer with a fast and maximum force and the values that were seen were recorded. Two trials were made for the same hand and their 30-second rests between the trials were allowed. The maximum value was recorded as the maximal paw force in $\mathrm{kg}$ (Zorba, 2000).

\subsubsection{Vertical Jump Test}

Vertical jumping measurement of the athletes who participated in the study was carried out with a jump-meter from takei Physical Fitness Test Vertical (T.K.K.5106) after they were warmed up. Athletes stood on the rubber section of the jump-meter, and at the same time, the measuring part of the jump-meter was connected to their waist. The jump- meter rope was brought into the tight state and they were measured digitally and the values were recorded while the athletes jumped vertically by using their arms.

\subsubsection{Speed Run Test (30 m)}

The speed skills of the athletes participating in the survey were evaluated by a 30-meter running test. Athletes were taken to this test after they were warmed up. At a distance of $30 \mathrm{~m}$ the athletes were asked to start while standing at a distance of 1 meter from the starting line and to complete the distance with the highest speed. The ratings were determined in seconds with the Sport Expert (MPS 501) electronic photocell device. Each athlete repeated the test twice and the best result was assessed (Sever, 2013; Pancar, 2015).

\subsubsection{Stopping Long Jump Test}

The horizontal jump distance of the athletes participating in the survey was measured in centimeters. Athletes were taken to this test after they were warmed up. Behind the starting line, the feet are moved bilaterally straight, like the handles of the hand, and it was desired to fix the horizontal jump from the athlete without loosing the balance (Reimanend Manske 2009). The starting line and the distance which the athlete leaped was measured. The athlete was given two rights of trying. The best jump distance was taken as the test score (Tamer, 2000).

\subsubsection{Flexibility Test}

Flexibility performance measurement of the athletes participating in the survey was done by sit-reach test on the elasticity platform. Athletes were taken to this test after they were warmed up. In the case of straddling the bare soles from the athletes to the test bench seated at the top, it is desirable to reach the maximum forwards without twisting their knees. The test measurement was recorded by waiting for two seconds in the maximum reaching position. The test was repeated three times and the highest value was recorded (Özer, 2001).

\subsubsection{Standing Healthy Top Double Handed Head Test}

The athlete's health ball ( $3 \mathrm{~kg}$ ) was taken on the specified line, with the feet in the same line, taking the arms backwards. Then the ball was thrown forward with double hand with maximal power (Sevim and Şengül, 1987). The distance between the stopping point and the place where the ball was thrown was measured. The result was determined in meters (Sevim, 1992).

\subsubsection{Standing health ball One Hand (Dominant Hand) Heading Test}

The athlete threw the ball of health $(3 \mathrm{~kg}$ ) forward with one hand at maximum power, with the feet aligned in line (Sevim and Şengül, 1987). The distance the ball was throw was measured. Result (m) was determined (Sevim,1992).

\subsubsection{Shuttle Test}

This test measures the strength and durability of the abdominal muscles; on the back on the mat, the knees flexed the body when it was about 90 degrees in flexion position (Ergun, 2011). The correct number of repetitions within 30 seconds was recorded as the maximum number of shuttles, counting each body flexure together with the mark (Henderson et al. 2007).

\subsubsection{Reverse Shuttle Test}

The test was done with reverse shuttle motion. The athletes were told to lift and lower their trunk backwards in a twist on the mat, while the hands were secured and the feet were united. Accurate repetitions within 30 seconds were recorded as the maximum number of reverse shuttles, counting every move with the mark (Henderson et al. 2007). 


\subsection{Evaluation of Research Data}

In the analysis of the data, SPSS package program was used. Student's-t test was applied to compare the pre-training (first) and post-training (post) training of the training group and core training groups. A paired sample (dependent sample) $t$ test was used to compare the first and last tests of both groups.

\section{Results}

\subsection{Statistics of Pre-Test and Post-Test Parameters of Volleyball Players}

Table 1. Comparison of Pretreatment Parameter Levels of Volleyball Training Group and Core Training Group

\begin{tabular}{|c|c|c|c|}
\hline Parametreler & $\begin{array}{l}\text { V. Antrenman Grubu İlk Test } \\
\bar{X} \pm \operatorname{SEM}(n=17)\end{array}$ & $\begin{array}{l}\text { K. Antrenman Grubu İlk Test } \\
\bar{X} \pm \operatorname{SEM}(n=17)\end{array}$ & $\mathbf{P}$ \\
\hline BKI & $21.10 \pm 1.26$ & $21.40 \pm 0.98$ & 0,852 \\
\hline Dominant Hand Grip Strength (kg) & $28.08 \pm 1.03$ & $27.48 \pm 1.42$ & 0,733 \\
\hline Non Dominant Hand Grip Strength (kg) & $24.65 \pm 0.90$ & $24.17 \pm 1.35$ & 0,770 \\
\hline Vertical Jump (cm) & $40.70 \pm 1.67$ & $40.59 \pm 1.66$ & 0,960 \\
\hline Speed Test Over & $5.18 \pm 0.08$ & $5.19 \pm 0.07$ & 0,905 \\
\hline Standing Long Jump & $1.52 \pm 5.33$ & $1.52 \pm 5.40$ & 0,975 \\
\hline Flexibility (cm) & $26.00 \pm 1.24$ & $26.89 \pm 1.01$ & 0,586 \\
\hline Standing Dual Hand health ball test (m) & $4.09 \pm 0.18$ & $4.12 \pm 0.23$ & 0,921 \\
\hline Dual Hand health ball & $4.70 \pm 0.12$ & $4.69 \pm 0.16$ & 0,719 \\
\hline Sit-up (30 sn) & $31.47 \pm 1.42$ & $31.18 \pm 1.28$ & 0,875 \\
\hline Reverse Sit-up(30 & $34.41 \pm 1.42$ & $33.41 \pm 1.44$ & 0,624 \\
\hline
\end{tabular}

According to Table 1, there was no statistically significant difference between the results of the first test (all parameters) of female volleyball players participating in the study ( $p>0.05$ ).

Table 2. Comparison of final test parameters of volleyball training group and core training group

\begin{tabular}{lllc}
\hline & V. Antrenman Grubu Son Test & \multicolumn{2}{c}{ K. Antrenman Grubu Son Test } \\
Parametreler & $\bar{X} \pm$ SEM $(\mathbf{n = 1 7})$ & $\bar{X} \pm$ SEM (n=17) & P \\
\hline BKI & $21.00 \pm 1.06$ & $20.04 \pm 0.84$ & 0,482 \\
Dominant Hand Grip Strength (kg) & $28.69 \pm 1.02$ & $34.05 \pm 1.48$ & $0,005^{*}$ \\
Non Dominant Hand Grip Strength & $24.82 \pm 0.89$ & $30.69 \pm 1.53$ & $0,002^{*}$ \\
Vertical Jump (cm) & $41.29 \pm 1.84$ & $48.23 \pm 1.84$ & $0,012^{*}$ \\
Speed Test Over 30 & $5.12 \pm 0.09$ & $5.16 \pm 0.06$ & 0,697 \\
Standing Long Jump & $1.53 \pm 5.06$ & $1.64 \pm 5.53$ & 0,146 \\
Flexibility (cm) & $26.76 \pm 1.19$ & $27.94 \pm 1.36$ & 0,520 \\
Standing Dual Hand health ball test $(\mathbf{m})$ & $4.28 \pm 0.18$ & $5.08 \pm 0.17$ & $0,003^{*}$ \\
Dual Hand health ball & $4.88 \pm 0.13$ & $5.63 \pm 0.21$ & $0,004^{*}$ \\
Sit-up (30 sn) & $32.65 \pm 1.45$ & $38.88 \pm 1.43$ & $0,004^{*}$ \\
Reverse Sit-up(30 & $34,82 \pm 1,48$ & $40.18 \pm 1.44$ & $0,014^{*}$ \\
\hline
\end{tabular}

Table 2 was examined, there was no statistically significant difference between volleyball training group and core training group post-test values in body fat percentage analysis, $30 \mathrm{~m}$ running test, standing long jump test and sit- reach test parameters $(\mathrm{p}>0.05)$.

When Table 2 is examined, statistically between dominant hand grip strength, non dominant hand grip strength, vertical jump test, dominant hand health ball test, double hand health ball test, shuttle test and reverse shuttle test parameters, volleyball training group and core training group post test values was found to be a significant difference $(\mathrm{p}<0.05)$. 
Table 3. Comparison of Pre-Test and Post-Test Parameters of the Core Training Group

\begin{tabular}{llll}
\hline & K. Antrenman Grubu İlk Test & \multicolumn{2}{l}{ K. Antrenman Grubu Son Test } \\
& $\bar{X} \pm$ SEM (n=17) & $\bar{X} \pm$ SEM (n=17) & P \\
\hline BKI & $21.40 \pm 0.98$ & $20,04 \pm 0.84$ & $0,004^{*}$ \\
Dominant Hand Grip Strength (kg) & $27,48 \pm 1,42$ & $34,05 \pm 1,48$ & $0,000^{*}$ \\
Non Dominant Hand Grip Strength (kg) & $24,17 \pm 1,35$ & $30,69 \pm 1.53$ & $0,000^{*}$ \\
Vertical Jump (cm) & $40,59 \pm 1,66$ & $48,23 \pm 1,84$ & $0,000^{*}$ \\
Speed Test Over 30 m (sn) & $5,19 \pm 0.07$ & $5,16 \pm 0.06$ & 0,539 \\
Standing Long Jump (cm) & $1,52 \pm 5,40$ & $1,64 \pm 5,53$ & $0,000^{*}$ \\
Flexibility (cm) & $26,89 \pm 1,01$ & $27,94 \pm 1,36$ & 0,105 \\
Standing Dual Hand health ball test (m) & $4,12 \pm 0.23$ & $5,08 \pm 0.17$ & $0,000^{*}$ \\
Dual Hand health ball test (m) & $4,69 \pm 0.16$ & $5,63 \pm 0.21$ & $0,000^{*}$ \\
Sit-up (30 sn) & $31,18 \pm 1,28$ & $38,88 \pm 1.43$ & $0,000^{*}$ \\
Reverse Sit-up(30 & $33,41 \pm 1,44$ & $40.18 \pm 1.44$ & $0,000^{*}$
\end{tabular}

Table 3 was examined, it was seen that there was no statistically significant difference between the first and last test values of the core training group in the $30 \mathrm{~m}$ running test and the sit-reach test parameters ( $p>0.05)$. When Table 3 was examined, the body fat percentage, dominant hand grip strength, non dominant hand grip strength, vertical jump test, standing long jump test, dominant hand health ball test, double hand health ball test, shuttle test and reverse shuttle test, were found that there was a statistically significant difference between the first and last test values of the core training group in the parameters $(\mathrm{p}<0,05)$.

Table 4. Comparison of pre-test and post-test parameter levels of the volleyball training group

\begin{tabular}{llll}
\hline & V. Antrenman Grubu Illk Test & V. Antrenman Grubu Son Test \\
& $\bar{X} \pm \operatorname{SEM}(\mathbf{n}=\mathbf{1 7})$ & $\overline{\mathrm{X}} \pm \mathbf{S E M}(\mathbf{n = 1 7})$ & $\mathbf{P}$ \\
\hline BKI & $21.10 \pm 1,26$ & $21,00 \pm 1,06$ & 0,707 \\
Dominant Hand Grip Strength (kg) & $28,08 \pm 1,03$ & $28,69 \pm 1,02$ & 0,055 \\
Non Dominant Hand Grip Strength (kg) & $24,65 \pm 0.90$ & $24,82 \pm 0.89$ & 0,559 \\
Vertical Jump (cm) & $40,70 \pm 1,67$ & $41,29 \pm 1,84$ & 0,434 \\
Speed Test Over 30 m (sn) & $5,18 \pm 0.08$ & $5,12 \pm 0,09$ & 0,294 \\
Standing Long Jump (cm) & $1,52 \pm 5,33$ & $1,53 \pm 5,06$ & 0,526 \\
Flexibility (cm) & $26,00 \pm 1,24$ & $26,76 \pm 1,19$ & 0,109 \\
Standing Dual Hand health ball test (m) & $4,09 \pm 0.18$ & $4,28 \pm 0.18$ & 0,075 \\
Dual Hand health ball test (m) & $4,70 \pm 0.12$ & $4,88 \pm 0.13$ & $0,020^{*}$ \\
Sit-up (30 sn) & $31,47 \pm 1,42$ & $32,65 \pm 1,45$ & 0,104 \\
Reverse Sit-up(30) & $34,41 \pm 1,42$ & $34,82 \pm 1,48$ & 0,507 \\
\hline
\end{tabular}

When examined in Table 4, parameters such as body fat percentage, dominant hand grip strength, non dominant hand grip strength, vertical jump test, $30 \mathrm{~m}$ running test, standing long jump test, sit-reach test, dominant hand health ball test, shuttle test and reverse shuttle test parameters there was no statistically significant difference between the first and last test values of the volleyball training group $(p>0.05)$.

Table 4 was examined, it was seen that there was a statistically significant difference between pre and post test values of volleyball training group in double hand health ball test $(\mathrm{p}<0,05)$.

\section{Discussion}

In this study, we investigated the effect of 10 -week core training on the jump forces and some motoric features of female volleyball players aged 14-16 years. Pre and post tests of control group who just train for volleyball three days a week and experimental group who train for volleyball three days a week as well as core training were compared. In addition, before-training (pre-test) and after-training (post-test) tests were compared for each group separately. The exercises in 
core training program prepared for the core training group, the way the exercises are implemented, the number of trainings, the duration and intensity of trainings fit for training principles. Van Pletzen and Venter's study (2012) have indicated that the jump performance of the athletes with more core muscle strength is better. Hoshikava and his colleagues (2013) applied only soccer training for the control group for 6 months and the core training to the regular training program for the experimental group in the study of 12-13 year old soccer players. It was found that there was a statistically significant difference between the vertical jump distances of the groups $(\mathrm{p}<0.05)$.

There was no statistically significant difference between standing long jump test results of the VTG and CTG groups' after-training (post-test) ( $p>0.05$ ). However, there was a statistically significant difference between standing long jump test results of CTG group's before-training (pre-test) and after-training (post-test) (p <0.05). There was no statistically significant difference between standing long jump test results of VTG group's before-training (pre-test) and after-training (post-test) ( $\mathrm{p}>0.05)$.

In our study, after 10-week core exercise, lower extremity muscle strength and jump strength were found to develop. Pedersen et al. (2006) found that 8-week core training increased elbow muscle strength of elite soccer players, thus indicated that their shoot speeds have improved. In a study carried out on cyclists, it is recommended that core exercises should be applied to improve painless strength development and performance (Preis et al. 2012). In another study conducted on the university volleyball team, the effect of the core training applied with 9-week regular training on the vertical jump was found to be significant $(\mathrm{p}<0.05)$. It can be said that core training develops lower extremity muscle strength, accordingly the vertical jump (Sharma et al. 2012).

A statistically significant difference was found between the VTG group and the CTG group when after-training (post-test) dominant hand grip strength test results of the VTG group and the CTG group were compared ( $p<0.05)$. There was a statistically significant difference between before-training (pre-test) and after-training (post-test) dominant hand grip strength test results of CTG group ( $p<0.05$ ). There was no statistically significant difference between before-training (pre-test) and after-training (post-test) dominant hand grip strength test results of VTG group ( $p>0.05$ ).

According to our study, it has been understood that 10 -week core exercise has a positive effect on the dominant and non dominant grip strength and increases hand grip strength. In a study conducted on sedentary individuals, it has been stated that an 8-week core-plyometric exercise develops right and left hand grip strength (Afyon and Boyac1, 2013).

According to our study, it has been determined that 10-week core exercise contributes to the development of upper extremity muscle strength. In a study carried out on young golfers, 9-week core training has been reported to increase ball travel speed. The increase in ball speed during stroke is due to the development of upper extremity muscle strength (Seiler et al. 2006).

Afyon and Boyac1 (2013) have reported in their study that 8-week core-plyometric exercise increases the number of pull-ups and push-ups and thus improves upper extremity muscle strength. In another study on elite female golfers, it has been stated that the core training applied for 12 weeks improves the shooting distance. The increase in ball shot distance is related to the development of upper extremity muscle strength (Kim, 2010). In their study, Van Pletzen and Venter (2012) have found that the athletes with higher core muscle strength have more numbers of pull-ups. In this context, it can be said that there is an important relation between core exercise and upper extremity muscle strength.

According to our study, it has been determined that the 10-week core exercise program doesn't improve the flexibility feature. In a study on elite female golfers, it has been stated that core training applied for 12 weeks developes flexibility (Kim, 2010). Afyon and Boyac have stated in their study that the 8-week core-plyometric exercise improves the flexibility feature. The results of our study do not coincide with the results of the studies mentioned above. We can say that this difference may be due to the fact that the core workouts are not supported by stretching exercises or that the warm-up protocols are different.

As noted in this and other similar studies, it has clearly been stated that core training has an important contribution to the development of sportive performance of athletes in different age groups. Core exercises, especially done with body weights, support the physical development of the athletes in their developmental periods by ensuring optimum performance. We can say that infrastructure trainers in different sports branches should include core training in their own training programs.

\section{References}

Afyon, Y. A. (2014). Effect of core training on 16 year-old soccer players. Educational Research and Reviews, 9(23), $1275-1279$.

Afyon, Y. A., \& Boyaci, A. (2013). Investigation of the effects by compositely edited core-plyometric exercises in sedentary man on some physical and motoric parameters. International Journal of Academic Research Part A, 5(3), 256-261. https://doi.org/10.7813/2075-4124.2013/5-3/A.37 
Atli, M., Temur, H. B., Gencer, G., \& Şensoy, N. (2011). The Comparison of Biometric Characteristics of Yüzüncü Yıl University Tennis Team Players to Sedentary People. Yüzüncü Yll University Journal of Education Faculty. Special Volume, 175-181.

Bilgiç, M., Pancar, Z., Şahin, F. B., \& Özdal, M. (2016). Investigation of Coorelation Between Two Different Anaerobic Power Tests in Sedentary Children. Gaziantep University Journal of Sports Sciences, 1(2), 40-48.

Gencer, Y. G., \& Asma, M. B. (2017). The Comparison Of Some Motoric And Technical Characteristics Between 12 Dev Adam And Tofas Basketball Scholls (Van Sample). European Journal of Physical Education and Sports Sciences, 3(11), 262-271.

Henderson, N. D., Berry, M. W., \& Matic, T. (2007). Field measures of strength and fitness predict firefighter performance on physically demanding tasks. Personel Psychology, 60(2), 431-473. https://doi.org/10.1111/j.1744-6570.2007.00079.x

Hoshikawa, Y., Lida, T., Muramatsu, M., Ii, N., Nakajima, Y., Chumank, K., \& Kanehisa, H. (2013). Effects of stabilization training on trunk muscularity and physical performances in youth soccer players. Journal of Strength and Conditioning Research, 27(11), 3142-3149. https://doi.org/10.1519/JSC.0b013e31828bed36

Kim, K. J. (2010). Effects of core muscle strengthening training on flexibility, muscular strength and driver shot performance in female professional golfers. Int. J. Appl. Sport Sci., 22, 117-127.

Mcgill, S. (2010). Core training: Evidence translating to better performance and injury prevention. Journal of Strength and Conditioning Research, 32(3), 33-46. https://doi.org/10.1519/SSC.0b013e3181df4521

Özer, K. (2001). Physical activity. Ankara: Nobel publishing and distribution.

Özer, Y., Bozdal, Ö., \& Pancar, Z. (2017). Acute Effect Of Circuit Aerobic And Traditional Aerobic Training On Hamstring Flexibility In Sedentary Women. European Journal Of Physical Education And Sports Sciences, 3(12), 268-275.

Pancar, Z. (2015). Effect of 8 Weeks Plyometric Training on Anaerobic Power, Balance and Sprint Performance of Aged 12- 14 Female Handball Players, Gaziantep University Health Science Institute.

Pancar, Z., Bozdal, Ö., Biçer, M., \& Akcan, F. (2017). Acute Effect Of Anaerobic Exercise On Dynamic Balance Of Sedentary Young Boys. European Journal Of Physical Education And Sport Science, 3(12), 229-237.

Pancar, Z., Özdal, M., Pancar, S., \& Biçer, M. (2016). Investigation Of Visual And Auditory Simple Reaction Time Of 11-18 Aged Youth. European Journal Of Physical Education And Sport Science, 2(4), 145-152.

Pedersen, J. L. S., Magnussen, R., Kuffel, E., \& Seiler, S. (2006). Sling exercise training improves balance, kicking velocity and torso stabilization strength in elite soccer players. Med. Sci. Sports Exerc., 38, 243-251. https://doi.org/10.1249/00005768-200605001-01945

Preis, C., Macedo, R., Duarte, J., Ricieri, D., \& Bertassoni, L. (2012). Core exercises in cyclists and triathletes. Physical Therapy in Sport, 13, 3.

Reiman, M. P., \& Manske, R. C. (2009). Functional testing in human performance. United states: Human Kinetics Champaign.

Sarikaya, M., Çınar, V., \& Selçuk, M. (2016). Examination on the effect of the training program implemented during preparation period on the physical characteristics of tennis players. International Journal of Sport Studies, 6(10), 607-611.

Sarikaya, M., Selçuk, M., Gencer, Y. G., Temur, H. B., \& Öntürk, U. (2017). The Effect Of 8 Week Tennis Technical Training And Games On Reaction Time In 10-12 Year Old Boys. European Journal of Physical Education and Sport Science, 3(12), 470-477.

Seiler, S., Skaanes, P. T., \& Kirkesola, G. (2006). Effects of sling exercise training on maximal club head velocity in junior golfers. Med. Sci. Sports Exerc., 38, 286-292. https://doi.org/10.1249/00005768-200605001-02115

Sever, O. (2013). Investigation of footballers' level of physical fitness according to the variables of position and age. Gazi University. Master's Thesis.

Sevim, Y. (1992). Training Knowledge Lecture Notes. Ankara: Gazi office bookstore.

Sevim, Y., \& Şengül, E. (1987) Exercises of Build-up with Med Ball. Ankara: G.S.G.M. Department of Sports Education Publishing. 
Sharma, A., Geovinson, S. G., \& Singh, S. J. (2012). Effects of a nine-week core strengthening exercise program on vertical jump performances and static balance in volleyball players with trunk instability. J. Sports Med. Phys. Fitness, 52(6), 606-615.

Tamer, K. (2000). Measurement and evaluation of physical physiological performance in sports. Ankara: Bağırgan Publishing House.

Van, P. D., \& Venter, R. (2012). The relationship between the bunkie-test and physical performance in rugby union players. Int. J. Sports Science \& Coaching, 7(2), 545-555.

Zorba, E. (2000). Physical Activity. Ankara: Muğla University Publications.

Zorba, E. (2005). Physical Activity. Ankara: Gazi Bookstore.

\section{Copyrights}

Copyright for this article is retained by the author(s), with first publication rights granted to the journal.

This is an open-access article distributed under the terms and conditions of the Creative Commons Attribution license which permits unrestricted use, distribution, and reproduction in any medium, provided the original work is properly cited. 